\title{
Psychosocial Interventions to Prevent Anxiety Disorders in School Settings from 1985-2007: A Meta-Analysis
}

\section{Intervenciones Psicosociales para Prevenir Desordenes de Ansiedad en Configuraciones de la Escuela a partir de 1985- 2007: Un Meta-Análisis}

\author{
Julia Gallegos \\ Universidad de Monterrey, México \\ Tasha Beretvas \\ University of Texas at Austin, USA
}

\author{
Raquel Benavides \\ Universidad Autónoma de Nuevo León, México \\ Sylvia Linan-Thompson \\ University of Texas at Austin, USA
}

\begin{abstract}
Childhood anxiety disorders are a salient concern because they are associated with deviant conduct, substance abuse, and depression later in life. This meta-analysis focuses on the efficacy of psychosocial interventions in preventing anxiety disorders in children. A search of several databases covering 19852007 identified 19 peer-reviewed studies. Most of the studies were judged with "Low Risk of Bias". Results showed CBT to be the most effective psychosocial intervention (95\% CI, 0.19 a 0.43 ), particularly when implemented at a selective prevention level $(95 \% \mathrm{CI}, 0.20$ a 0.97$)$. The protective factors to improve the most were positive future outlook (95\% CI, 0.87 to 1.51) and self-esteem (95\% CI, 0.87 a 1.51). Suggestions for further research and implications for practice are offered.

Keywords: meta-analysis, anxiety, childhood, prevention, psychosocial interventions.
\end{abstract}

\begin{abstract}
Resumen. Los trastornos de ansiedad en la infancia han sido un tema de preocupación ya que están asociados con la conducta desafiante, el abuso de sustancias y la depresión en edad adulta. El presente metaanálisis se enfoca en la eficacia de las intervenciones psicosociales para la prevención de los trastornos de ansiedad en la infancia. Se realizó una búsqueda en diferentes bases de datos cubriendo de 1985 al 2007 y se identificaron 19 estudios de investigación publicados en revistas con arbitraje. La mayoría de los estudios fueron juzgados con "bajo riesgo de sesgo". Los resultados del presente estudio muestran que la mejor intervención psicosocial es la cognitivo-conductual (95\% IC, 0.19 a 0.43), particularmente cuando se implementa en el nivel de prevención selectivo (95\% IC, 0.20 a 0.97). Los factores de protección que mostraron mayor mejora fueron el optimismo (95\% IC, 0.87 a 1.51 ) y la autoestima (95\% IC, 0.87 a 1.51 ). Se ofrecen sugerencias tanto para futuras investigaciones como para implicaciones en la práctica.

Palabras clave: meta-análisis, ansiedad, infancia, prevención, intervenciones psicosociales.
\end{abstract}

\section{Introduction}

A growing number of school-aged children experience or are at risk for myriad of psychological and behavioral problems that interfere with their interpersonal relationships, school performance, and potential for becoming productive citizens (Garland et al., 2001; National Institute of Mental Health, 1999; World Health Organization, 2004). Anxiety disorders are among the most prevalent psychiatric disorders in children and adolescents, with up to $25 \%$ of children experiencing clinical anxiety at some point (Boyd, Kostanski, Gullone, Ollendick, \& Shek, 2000; Essau, Conradt, \& Petermann, 2000; Neil \& Christensen, 2009; Tomb \& Hunter, 2004). This issue is compound by the fact that many children with anxiety disorders

Correspondence on this paper should be sent to Julia Gallegos, Benalcazar 115 pte. Colonia Mirasierrra, San Pedro Garza García, Nuevo León. C.P. 66240. E-mail: gallegosjulia@gmail.com do not received the treatment they require (Kessler et al, 2005). Untreated anxiety can compromise social, emotional and academic functioning (Donovan \& Spence, 2000), resulting from poor social and coping skills, low self-esteem, social isolation and academic underachievement (Mc Loone et al., 2006; Rapee et al., 2005). These factors could limit vocational opportunities and contribute toward the development of deviant conduct, substance abuse, and depression later in life (Burke, Burke, \& Rae, 1994; Caraveo-Anduaga \& Comenares-Bermúdez, 2002; Kashani \& Orvaschel, 1990; World Health Organization, 2004), hence, early prevention and intervention in schools are critical.

Experiencing some anxiety is part of the normal development of the human being, however, anxiety responses become problematic when they persistently occur in response to an unreasonable perception of threat, and at an intensity that is disproportionate to the objective threat (Essau \& Peterman, 2001). In this way, anxiety ceases to be adaptive, resulting in func- 
tional impairment and interfering with aspects of everyday life. According to the tripartite model, anxiety disorders share three major factors: cognitive ideation, physiological features, and behavioral responses (Ollendick, Shortt, \& Sander, 2005). The development and maintenance of anxiety disorders is characterized by the interaction between the personal characteristics of the child, such as genetic vulnerability, behavioral inhibition, and cognitive process, and interpersonal factors such as attachment to caregivers and learning processes that occur in the family. Anxious children tend to overestimate the threat and underestimate their coping ability and frequently come from families in which parents are restrictive and overprotective (Barrett, Dadds, \& Rapee, 1996), which prevents the development of coping behaviors (Kendall \& Suveg, 2006; Ollendick, Shortt, \& Sander, 2005).

Research on risk and protective factors indicate that the presence of behavioral inhibition, attentional and interpretation bias, parental psychopathology, parenting practices that reinforce anxious and avoidant behaviors, insecure attachment, living in a socioeconomically disadvantaged community, and negative life events are major risk factors for the development of an anxiety disorders (Barrett \& Turner, 2004; Curtis et al., 2000; Donovan \& Spence, 2000; Kessler, 1982). On the other hand, protective factors such as social support, secure attachment to a parent or caregiver, good self-esteem and self-concept, positive future outlook, locus of control, emotional regulation, and positive and proactive coping skills have shown to enhanced the emotional resilience of the child at risk and prevent the onset of an anxiety disorder (Barrett \& Turner, 2004; Bernstein, Borchardt, \& Perwien, 1996; Donovan \& Spence, 2000; Masten, 2001). Anxiety disorders are often associated with other types of disorders that are frequently present in schools: depression, learning disabilities (LD), ADHD, oppositional defiant disorder, and conduct disorders (Craske, 1999; Noel, Hoy, King, Moreland, \& Jagota, 1992).

Psychosocial interventions have been conducted as preventive strategies in schools under the rationale that reducing anxiety symptoms may be an effective way to prevent problems that many people experience later in life (Dozois \& Westra, 2004). Three levels of prevention have been identified: universal, selective and indicated (Gordon 1987; Barrett \& Farrell, 2007). Universal prevention involves the treatment of an entire population of individuals, regardless of differences in diagnostic status or risk. The goal is to reduce risk factors for anxiety through targeting symptoms and building social and emotional resilience, thereby reducing both the incidence and prevalence of anxiety disorders. By comparison, selective prevention focuses on a subset of the population who, whilst not yet displaying symptoms of a diagnosable disorder, have existing identifiable risk factors for anxiety (e.g. experiencing a negative life event, parental psychopathology). Lastly, indicated prevention is targeted at individuals already experiencing clear signs or symptoms of anxiety, who are therefore at greatest risk of developing a diagnosable disorder.

Studies focusing on the prevention of anxiety disorders with primary-school children have explored the effects of behavioral (e.g., relaxation), social skills training (SST), Eye Movement Desensitization and Reprocessing (EDRM), and cognitive-behavioral (CBT) interventions.

Behavioral interventions such as relaxation training help children to manage stress and reduce anxiety. This type of intervention teaches children to increase the discrimination of arousal cues (e.g., increased heart rate) and to decrease the faulty misinterpretations through abdominal breathing and mental imagery (Ragan \& Hiebert, 1987). EDRM is a brief psychotherapy that incorporates elements of cognitive-behavioral and psychodynamic treatments (Shapiro, 1995). In EDRM is required a paced exposure treatment were participants are asked to identify a distressing memory and related imagery and sensations, this, followed by a set of eye movements. CBT interventions teaches children to recognize anxious behaviors and physiological reactions, clarify maladaptive cognition and negative self-talk, develop a coping plan, and evaluate themselves in terms of partial success (Kendall, 2006). The SST intervention teaches children how to build friendships, body language interpretation, how to be assertive, and how to deal with bullying.

Although there have been reviews of empirical literatures on the prevention of childhood anxiety (e.g., Bernstein, Borchardt, \& Perwien, 1996; Feldner, Zvolensky \& Schimdt, 2004) no meta-analysis exist related to this issue. The purpose of this meta-analysis was to evaluate the efficacy of psychosocial interventions in reducing anxiety disorders in childhood (ages 6-12).

\section{Method}

To determine the relative efficacy of psychosocial interventions in reducing anxiety disorders in childhood, a meta-analysis was conducted. Studies included in this meta-analysis were selected according to the following set of criteria: (a) the focus was primarily on the psychosocial interventions in school settings with outcomes for anxiety (b) a controlled research design was used (i.e., randomized controlled trials or quasiexperimental design); (c) the primary sample was composed of children in elementary school grades between ages 6 and 12 (studies that included adolescent samples were also included if results were analyzed and reported separately for children and adolescents or the mean age of the sample was less than 13); (d) studies 
were published in English-language peer-reviewed journals.

The first resource for this meta-analysis was the synthesis conducted by Compton, Burns, Egger, and Robertson (2002), which focused on treatments of childhood anxiety and depression. The Compton et al. (2002) synthesis was used to identify keywords for the computer search and components for the analysis of the studies.

The Psychological Information Abstracts (PsychInfo), Educational Resource Information Center (ERIC), and MEDLINE online databases were systematically scanned for studies from 1985 and 2007 that met the inclusion criteria described above.

For the computer search, the following terms were used: anxiety disorder, anxiety, separation anxiety, anxiety neurosis, generalized anxiety disorder, Obsessive-Compulsive Disorder (OCD), panic disorder, phobias, Post-Traumatic Stress Disorder (PTSD), social anxiety, school refusal, and elective mutism.

\section{Analysis Procedures}

Effect sizes were used to compare the efficacy of different types of psychosocial interventions across studies. Standardized effect size estimates were calculated using Cohen's $d$ and computed as $d=\frac{\left(M_{T}-M_{C}\right)}{S D}$ where $M_{T}$ is the mean of the treatment group, $M_{C}$ is the mean of the comparison group, and $S D$ is the pooled within groups standard deviation (Cohen, 1992). When results were provided for subsamples (e.g. Chinese and Former-Yugoslavian in Barrett, Sonderegger and Xenos, 2003) a weighted average was calculated using the following equation (1):

$$
\bar{d}_{W}=\frac{\left[\left(n_{T 1}+n_{C 1}\right) d_{1}+\left(n_{T 2}+n_{C 2}\right) d_{2}\right]}{\left[n_{T 1}+n_{C 1}+n_{T 2}+n_{C 2}\right]}
$$

When the subsample sizes of the treatment and control groups were not provided but the total subsample size was provided, then half of the total subsample was used as the sample sizes for the treatment and control groups (e.g. Lock and Barrett, 2003). When lower scores on a measure indicated a positive outcome, then the sign of the resulting $d$ was corrected to reflect this.

When means and standard deviations were not reported, other data were entered to compute effect sizes (e.g., proportion of participants whose diagnosis changed). For outcome data presented as changes in rate of diagnosis through $\chi 2$, the following equation (2) was used (Lipsey \& Wilson, 2000):

$$
\left|E S_{\chi^{2}}\right|=2 \sqrt{\frac{\chi^{2}}{\left(n_{T}+n_{C}-\chi^{2}\right)}}
$$

When the $\chi^{2}$ was not provided but percentages of change and samples sizes were available then $\chi^{2}$ was calculated by hand. A $\chi^{2}$ was calculated using following equation (3):

$$
\chi^{2}=\sum_{i=1}^{4} \frac{\left(f_{O_{i}}-f_{E_{i}}\right)^{2}}{f_{E_{i}}}
$$

Where $f_{O_{i}}$ is the observed frequency in cell $i$ and $f_{E_{i}}$ is the expected frequency in cell $i$. The studies by Stein, Jaycox, Kataoka, Wong, Tu, and Elliot (2005) and Misfud and Rapee (2005) did not provide enough data to calculate and verify effect sizes. For these studies, effect sizes reported by authors were used. Finally, estimated average of effect sizes, $\bar{d}$, which represents the weighted average of relevant effect sizes, were calculated for different categories of information, with a confidence interval of $95 \%$. The effect size was weighted by the inverse of the variance using the following equation:

$$
\bar{d}=\frac{\sum_{i} w_{i} d_{i}}{\sum_{i} w_{i}}
$$

where

$$
w_{i}=\frac{1}{\operatorname{var} d_{i}}
$$

To determine the confidence intervals the following equation was used:

$$
\bar{d} \pm z \bullet\left(S_{\bar{d}}\right)
$$

where

$$
S_{\bar{d}}=\sqrt{\frac{1}{\sum d_{i}}}
$$

and $\mathrm{z}(=1.96)$ is the critical value from the normal distribution such that the area between $-\mathrm{z}$ and $\mathrm{z}$ is equal to $95 \%$. The following equation was used:

$$
Q=\sum\left[w_{i}\left(d_{i}-\bar{d}\right)^{2}\right]
$$

Additionally, we tested the homogeneity between studies using a Ji-squared distribution with k-1 degrees of freedom where $\mathrm{k}$ is the number of the sizes of the effect. A large value for $\mathrm{Q}$ indicates that there is significant heterogeneity between the studies. To incorporate and evaluate Q and other sources of heterogeneity the random effects model of DerSimonian and Laird was used (DerSimonian \& Laird, 1986). 


\section{Results}

The results from this search yielded 3,417 abstracts; title and abstracts for this initial pool were then examined to determine the appropriateness for inclusion. Studies conducted in clinical settings and studies focusing on test anxiety rather than anxiety as a psychological disorder were excluded. Studies that met the criteria but did not provide enough information to compute effect sizes were also excluded. Two of these studies (Dadds et al., 1999; Dadds, Spence, Holland, Barrett, \& Laurens, 1997) were also integrated in the Compton et al. (2002) synthesis. Studies that included both primary and secondary students were included if results were disaggregated by age and effect sizes could be computed for students in primary school.

\section{Characteristics of Studies}

There were included and analyzed a total of 19 randomized controlled trial studies with 4,198 participants (6-14 years). The main characteristics of included studies are reported in Table 1 . Studies were published from 1987 to 2006 and most of them were carried out in United States. Most of the studies were conducted as Indicated prevention (8), seven Universal and the rest Selective.

\section{Assessment of Bias}

To assess the risk of bias, we used the indicators of the Cochrane Collaboration Manual (Higgins \& Altman, 2008), as table 2 shows. Most of the studies were judged as having Low Risk (L) of bias, which means that the published reports include all expected outcomes, including those that were pre-specified. Eight studies were categorized as having Unclear Risk (U) as they did not report all the prespecified outcomes. Finally only a few of them were classified as having High Risk $(\mathrm{H})$ of bias due to "other potential treats" such as an extreme baseline imbalance.

\section{Level of Prevention and Type of Psychosocial Intervention}

Table 3 shows the effect sizes for each level of prevention and each type of psychosocial intervention.

Table 1. Characteristics of Included Studies

\begin{tabular}{|c|c|c|c|c|c|c|}
\hline Study & Description & Duration & Participants & $\mathrm{nT}$ & $\mathrm{nC}$ & Outcome Measures \\
\hline 1. Ragan \& Hiebert (1987) & Universal. Behavioral. Teachers & $16 \mathrm{w}$ & 84 children Grades 1-3 & 65 & 19 & STAIC-T STAIC-S SPAS \\
\hline 2. Dadds et al. (1997) & Indicated. CBT. Psychologists & $10 \mathrm{w}$ & 128 children $7-14$ years & 61 & 67 & ADIS-P RCMAS CBCL CRC \\
\hline 3. Dadds et al. (1999) & Indicated. CBT. Psychologists $12 \& 24$ months follow-up & $10 \mathrm{w}$ & 128 children $7-14$ years & 61 & 67 & ADIS-P CRC \\
\hline 4. Lowry- Webster, Barrett \& Dadds (2001) & Universal. CBT. Teachers & $10 \mathrm{w}$ & 594 children $10-13$ years & 432 & 162 & SCAS CDI RCMAS \\
\hline 5. Barrett \& Turner (2001) & Universal. CBT. Teachers and Psychologists & $10 \mathrm{w}$ & 489 children $10-12$ years & 405 & 84 & SCAS RCMAS CDI \\
\hline 6. Lowry- Webster, Barrett \& Dadds (2003) & Universal. CBT. Teachers 12-months follow-up & $10 \mathrm{w}$ & 594 children $10-13$ years & 432 & 162 & SCAS RCMAS CDI ADIS-C \\
\hline 7. Fox \& Boulton (2003) & Selected. SST. Teachers/ trainers & $8 w$ & 28 children $9-10$ years & 15 & 13 & SPCC-GSW SPCC-SPSA RCMAI \\
\hline 8. Barrett, Sonderegger \& Xenos (2003) & Selected. CBT. Bilingual mental health professionals & $10 \mathrm{w}$ & 131 children $6-13$ years & 87 & 44 & RCMAS TSCL SEI KHS \\
\hline 9. Lock \& Barrett (2003) & Universal. CBT. Psychologists & $10 \mathrm{w}$ & 336 children $9-10$ years & 168 & 168 & SCAS RCMAS CSCY ADIS-C \\
\hline 10. DeCupyer et al. (2004) & Indicated. CBT. CBT therapists. & $16 \mathrm{w}$ & 20 children $9-10$ years & 9 & 11 & CDI SPPC STAIC-T CBCL-P \\
\hline 11. DeRosier (2004) & Selected. SST. School counselors. & $8 \mathrm{w}$ & 381 children $7-11$ years & 187 & 194 & Self-Efficacy Scale SASC SPPC-GSW \\
\hline 12. DeRosier \& Marcus (2005) & Selected. CBT. School counselors. 12-month follow-up & $8 w$ & 274 children $7-11$ years & 134 & 140 & $\begin{array}{l}\text { Self-Efficacy Scale SASC- With new peers } \\
\text { SASC- General SPPC-GSW }\end{array}$ \\
\hline 13. Ghaderi, Martensson \& Schwan (2005) & Universal. CBT. Teachers & $9 w$ & 153 children 11 years & 95 & 58 & MASC BSCI \\
\hline 14. Stein et al. (2005) & Indicated. CBT. School-based mental health clinicians & $10 \mathrm{w}$ & 126 children $10-11$ years & 61 & 65 & CPSS \\
\hline 15. Misfud \& Rapee (2005) & Indicated. CBT. School-based mental health clinicians & $8 w$ & 91 children $9-10$ years & 50 & 41 & $\begin{array}{l}\text { SCAS CATS- Anxiety CATS- Personal } \\
\text { Failure CATS- Hostile Intent TR- } \\
\text { Internalizing SCAS-P }\end{array}$ \\
\hline 16. Berstein et al. (2005) & Indicated. CBT. & $9 w$ & 61 children $7-11$ years & 37 & 24 & ADIS-C/P MASC-P SCARED-P CGI-P \\
\hline 17. Barrett et al. (2006) & Universal. CBT. Psychologists 24 months follow-up & $10 \mathrm{w}$ & 334 children $9-10$ years & 167 & 167 & SCAS RCMAS \\
\hline 18. Chemtob, Nakashima \& Carlson (2002) & $\begin{array}{l}\text { Indicated. Eye Movement Desensitization Reprocessing } \\
\text { (EDMR) Doctoral level clinicians. }\end{array}$ & $4 w$ & 32 children $6-12$ years & 17 & 15 & CRI RCMAS \\
\hline 19. Chemtob, Nakashima \& Hamada (2002) & Indicated. Postdisaster trauma treatment. Counselors. & $4 \mathrm{~s}$ & 214 children $6-12$ years & 176 & 73 & KRI CRI \\
\hline
\end{tabular}

Note: State-Trait Anxiety Scale (STAIC)/ Trait subscale (T)/ State subscale (S); Student's Perception of Ability Scale (SPAS); Anxiety Disorder Interview Schedule (ADIS) P- Parent Version/ C- Children Version; Revised Children's Anxiety Scale (RCMAS); Child Behavior Checklist (CBCL) P-Parent Version; Clinician's Ratings of Change on Overall Anxiety and Family Adjustment (CRC); Spence Children's Anxiety Scale (SCAS); Revised Children Manifest Inventory (RCMAI); Harter's Self-Perception Profile for Children (SPPC)/ Global Self-Worth subscale (GSW)/ Self-Perceived Social Acceptance subscale (SPSA); Trauma Symptom Checklist for Children (TSCL); Self-Esteem Inventory (SEI); The Kazdin Hopelessness Scale (KHS); Coping Scale for Children and Youth (CSCY); Social Anxiety Scale for Children (SASC); Multidimensional Anxiety Scale for Children (MASC); Beck Self-Concept Inventory (BSCI); Children PTSD Symptom Scale (CPSS); Anxiety Scale for Children's Automatic Thoughts (CATS); Teacher Report Form (TRF); Screen for Child Anxiety Related Emotional Disorders (SCARED); Clinical Global Impressions (CGI); Child Reaction Index (CRI); Kauia Reaction Inventory (KRI). 
Table 2. Assessment of Risk Bias

\begin{tabular}{|c|c|c|c|c|c|c|}
\hline \multicolumn{7}{|c|}{ Criteria for judging "Risk of Bias" } \\
\hline Study & $\begin{array}{c}\text { Sequence } \\
\text { Generation }\end{array}$ & $\begin{array}{l}\text { Allocation } \\
\text { Concealment }\end{array}$ & $\begin{array}{l}\text { Blinding of } \\
\text { Participants }\end{array}$ & $\begin{array}{l}\text { Incomplete } \\
\text { Outcome Data }\end{array}$ & $\begin{array}{l}\text { Selective } \\
\text { Outcome }\end{array}$ & $\begin{array}{l}\text { Other potentia } \\
\text { threats }\end{array}$ \\
\hline 1 & $\mathrm{U}$ & $\mathrm{U}$ & $\mathrm{L}$ & $\mathrm{L}$ & $\mathrm{L}$ & $\mathrm{H}$ \\
\hline 2 & $\mathrm{~L}$ & $\mathrm{~L}$ & $\mathrm{~L}$ & $\mathrm{~L}$ & $\mathrm{~L}$ & $\mathrm{~L}$ \\
\hline 3 & $\mathrm{~L}$ & $\mathrm{~L}$ & $\mathrm{~L}$ & $\mathrm{~L}$ & $\mathrm{~L}$ & $\mathrm{~L}$ \\
\hline 4 & $\mathrm{U}$ & L & $\mathrm{L}$ & $\mathrm{U}$ & $\mathrm{L}$ & $\mathrm{H}$ \\
\hline 5 & $\mathrm{~L}$ & $\mathrm{~L}$ & $\mathrm{~L}$ & $\mathrm{U}$ & $\mathrm{L}$ & $\mathrm{H}$ \\
\hline 6 & $\mathrm{U}$ & L & $\mathrm{L}$ & $\mathrm{L}$ & $\mathrm{L}$ & $\mathrm{H}$ \\
\hline 7 & $\mathrm{H}$ & $\mathrm{U}$ & $\mathrm{L}$ & $\mathrm{L}$ & $\mathrm{L}$ & $\mathrm{L}$ \\
\hline 8 & $\mathrm{U}$ & $\mathrm{L}$ & $\mathrm{L}$ & $\mathrm{L}$ & $\mathrm{L}$ & $\mathrm{L}$ \\
\hline 9 & $\mathrm{~L}$ & L & $\mathrm{L}$ & $\mathrm{L}$ & $\mathrm{L}$ & $\mathrm{H}$ \\
\hline 10 & $\mathrm{~L}$ & $\mathrm{U}$ & L & $\mathrm{L}$ & $\mathrm{L}$ & $\mathrm{L}$ \\
\hline 11 & $\mathrm{~L}$ & $\mathrm{U}$ & $\mathrm{L}$ & $\mathrm{L}$ & $\mathrm{L}$ & $\mathrm{H}$ \\
\hline 12 & $\mathrm{~L}$ & $\mathrm{U}$ & $\mathrm{L}$ & $\mathrm{L}$ & $\mathrm{L}$ & $\mathrm{H}$ \\
\hline 13 & $\mathrm{~L}$ & $\mathrm{~L}$ & L & $\mathrm{L}$ & $\mathrm{L}$ & $\mathrm{H}$ \\
\hline 14 & $\mathrm{~L}$ & $\mathrm{~L}$ & $\mathrm{~L}$ & $\mathrm{~L}$ & $\mathrm{~L}$ & $\mathrm{~L}$ \\
\hline 15 & $\mathrm{~L}$ & $\mathrm{~L}$ & $\mathrm{~L}$ & $\mathrm{~L}$ & $\mathrm{~L}$ & $\mathrm{~L}$ \\
\hline 16 & $\mathrm{~L}$ & $\mathrm{~L}$ & $\mathrm{~L}$ & $\mathrm{~L}$ & $\mathrm{~L}$ & $\mathrm{~L}$ \\
\hline 17 & L & L & L & $\mathrm{L}$ & $\mathrm{L}$ & L \\
\hline 18 & $\mathrm{~L}$ & $\mathrm{~L}$ & $\mathrm{~L}$ & $\mathrm{~L}$ & $\mathrm{~L}$ & $\mathrm{~L}$ \\
\hline 19 & $\mathrm{~L}$ & $\mathrm{~L}$ & $\mathrm{~L}$ & $\mathrm{~L}$ & $\mathrm{~L}$ & $\mathrm{~L}$ \\
\hline
\end{tabular}

H= High Risk, L= Low Risk, U= Unclear Risk

Table 3 Effect Sizes by Level of Prevention and Type of Psychosocial Intervention

\begin{tabular}{|c|c|c|c|c|c|c|c|c|}
\hline Level & Type of Tx & Group & Outcome & $k$ & $\begin{array}{l}\mathrm{ES} \\
\text { (post) }\end{array}$ & $\begin{array}{c}-95 \% \mathrm{CI}+95 \% \\
\text { (post) }\end{array}$ & $\begin{array}{c}\text { ES } \\
\text { (Follow-up) }\end{array}$ & $\begin{array}{c}-95 \% \text { CI }+95 \% \\
\text { (Follow-up) }\end{array}$ \\
\hline \multirow[t]{6}{*}{ Universal } & Beha-vioral & Mixed & $\begin{array}{l}\text { Anxiety } \\
\text { Protective }\end{array}$ & $\begin{array}{r}2 \\
\text { Not }\end{array}$ & 0.28 & $(-0.25,0.81)$ & - & - \\
\hline & \multirow[t]{5}{*}{$\mathrm{CBT}$} & \multirow[t]{2}{*}{ Mixed } & Anxiety & 14,6 & $0.31 *$ & $(0.19,0.43)$ & 0.04 & \multirow{5}{*}{$\begin{array}{l}(-0.27,0.34) \\
(-0.04,0.17) \\
(-1.72,0.47)\end{array}$} \\
\hline & & & Protective & 5,4 & -0.04 & $(-0.16,0.07)$ & 0.07 & \\
\hline & & \multirow[t]{2}{*}{ At-risk } & Anxiety & 5,2 & 0.19 & \multirow[t]{3}{*}{$(-0.23,0.62)$} & \multirow[t]{3}{*}{-0.63} & \\
\hline & & & Protective & & & & & \\
\hline & & Diag-Free & Anxiety & 1 & 0.15 & & & \\
\hline \multirow{5}{*}{ Selected } & \multirow{3}{*}{ SST } & \multirow{3}{*}{ At-risk } & & & & \multirow[b]{3}{*}{$(0.29,1.39)$} & \multirow{5}{*}{$\begin{array}{l}0.47^{*} \\
0.58^{*}\end{array}$} & \multirow{5}{*}{$\begin{array}{l}(0.18,0.76) \\
(0.20,0.97)\end{array}$} \\
\hline & & & Anxiety & 1 & -0.31 & & & \\
\hline & & & Protective & 2 & $0.84 *$ & & & \\
\hline & \multirow{2}{*}{$\mathrm{CBT}$} & \multirow{2}{*}{ At-risk } & Anxiety & 7,5 & 0.49 & $(-0.04,1.02)$ & & \\
\hline & & & Protective & 5,5 & $0.39 *$ & $(0.14,0.64)$ & & \\
\hline \multirow[t]{8}{*}{ Indicated } & \multirow[t]{4}{*}{$\mathrm{CBT}$} & \multirow[t]{2}{*}{ At-risk } & Anxiety & 25,13 & $0.26^{*}$ & $(0.10,0.43)$ & \multirow[t]{2}{*}{0.003} & \multirow[t]{2}{*}{$(-0.23,0.24)$} \\
\hline & & & Protective & & & & & \\
\hline & & \multirow[t]{2}{*}{ Diag-Anx } & Anxiety & 5,2 & $-0.33^{*}$ & $(-0.57,-0.10)$ & \multirow[t]{2}{*}{$-0.41^{*}$} & \multirow[t]{2}{*}{$(-0.66,-0.16)$} \\
\hline & & & Protective & & & & & \\
\hline & \multirow[t]{4}{*}{ EDRM } & At-risk & Anxiety & & & & & \\
\hline & & \multirow{3}{*}{ Diag-Anx } & Protective & & & & \multirow{3}{*}{-0.74} & \multirow{3}{*}{$(-1.77,0.28)$} \\
\hline & & & Anxiety & 2,2 & 0.49 & $(-1.32,2.29)$ & & \\
\hline & & & Protective & & & & & \\
\hline
\end{tabular}

Note: The first value in $k$ is the number of samples in outcome measures at posttest, and the second value at follow-up; $(*)=p<.05 ;(-)=$ not applicable, it was not measured.

Universal prevention programs that used cognitive and behavioral techniques (CBT) and included mixed groups reported a small to medium effect size after the intervention (95\% CI, 0.19 to 0.43 ), but gains were not maintained over time. However, when CBT is used as Selective prevention gains are maintained with a medium to large effect size (95\% CI, 0.20 to 0.97). Social Skills Training (SST) used as a selective 
prevention program showed a large effect size at posttest (95\% CI, 0.29 to 0.39 ). For Indicated prevention programs only those interventions that used CBT reported a small to large effect size at posttest $(95 \%$ CI, -0.57 to -0.10$)$ and at follow-up (95\% CI, -0.66 to $-0.16)$.

\section{Anxiety Outcome Measures by Prevention Level and Time Point}

Analyses were also conducted to see the impact of the interventions on the outcome measure of anxiety, taking into account the time of testing and the level of prevention (See table 4). For interventions implement-
In the same way, analyses were conducted for the protective factors outcome measures that were included in the studies: self-concept, self-esteem, positive future outlook, and coping skills (See table 5). Selfconcept presented a medium effect size (95\% CI, 0.12 to 0.33 ), a medium to large effect sizes was reported for self-esteem (95\% CI, 0.31 to 0.91 ) and a large effect size for positive future outlook $(95 \% \mathrm{CI}, 0.87$ to1.51).

For those interventions conducted as Universal prevention, the effect sizes were larger when the interventions were implemented by psychologists (.28, 95\% $\mathrm{CI}, 0.13$ to 0.43$)$ versus teachers $(.19,95 \% \mathrm{CI}, 0.02$ to $0.37)$. In addition, analyses were conducted to explore differences in the effect of preventing and reducing

Table 4. Effect Sizes for Anxiety Outcome Measures by Prevention Level and Time Point

\begin{tabular}{|c|c|c|c|c|}
\hline Level & Time Point & $\begin{array}{c}k \\
\text { (Number of samples) }\end{array}$ & ES & $-95 \% \mathrm{CI}+95 \%$ \\
\hline \multirow[t]{3}{*}{ Universal } & Post-intervention & 22 & $0.27 *$ & $(0.14,0.41)$ \\
\hline & 12-months follow-up & 7 & 0.02 & $(-0.22,0.27)$ \\
\hline & 24 months follow-up & 2 & $-0.40^{*}$ & $(-0.56,-0.25)$ \\
\hline \multirow[t]{3}{*}{ Selected } & Post-intervention & 8 & 0.39 & $(-0.09,0.87)$ \\
\hline & 4-months follow-up & 3 & $0.84 *$ & $(0.03,1.65)$ \\
\hline & 12-months follow-up & 2 & $0.36^{*}$ & $(0.19,0.53)$ \\
\hline \multirow[t]{5}{*}{ Indicated } & Post-intervention & 32 & $0.18^{*}$ & $(0.01,0.35)$ \\
\hline & 4-months follow-up & 5 & $0.46^{*}$ & $(0.14,0.77)$ \\
\hline & 6-months follow-up & 6 & $-0.34 *$ & $(-0.51,-0.17)$ \\
\hline & 12-months follow-up & 2 & -0.12 & $(-0.39,0.15)$ \\
\hline & 24 months follow-up & 3 & $-0.31 *$ & $(-0.55,-0.07)$ \\
\hline
\end{tabular}

Note: The value in $k$ is the number of samples in outcome measures; $(*)=p<.05$.

ed at the Universal prevention level the effect sizes were from small to medium at posttest (95\% CI, 0.14 to 0.41 ) and analyses showed that the intervention group got worse at 2-year follow-up (95\% CI,- 0.56 to -0.25). A large effect size was found at the Selective prevention level at 4-months follow-up (95\% CI, 0.03 to 1.65) and a small to large effect size at 12-months follow-up (95\% CI, 0.19 to 0.53 ). For the Indicated prevention level the intervention group showed improvements at 4-months follow-up but got worse at 6 and 24 months follow-up (95\% CI, -0.51 to -0.17 ; $95 \% \mathrm{CI},-0.55$ to -0.07 ; respectively).

Table 5. Effect Sizes for Protective Outcome Measures at All Levels of Prevention

\begin{tabular}{lccr}
\hline Protective Area & $\begin{array}{c}k \\
\text { (Number of } \\
\text { samples) }\end{array}$ & ES & $-95 \% \mathrm{CI}+95 \%$ \\
\hline Self-concept & 8 & $0.23^{*}$ & $(0.12,0.33)$ \\
Self-Esteem & 2 & $0.61^{*}$ & $(0.31,0.91)$ \\
Positive Future Outlook & 2 & $1.19^{*}$ & $(0.87,1.51)$ \\
Coping Skills & 8 & 0.001 & $(-0.08,0.08)$ \\
\hline
\end{tabular}

Note: The value in $k$ is the number of samples in outcome measures; $(*)=p<.05$. anxiety symptoms in different types of children at risk. Results showed significantly large effect sizes for immigrants from NESB and children with sub-threshold depression (See table 6).

\section{Discussion}

Anxiety disorders, the most prevalent form of psychopathology, have been identified as prominent matter as early anxiety problems are associated with

Table 6. Effect Sizes on Anxiety Outcome Measures for Different Type of Children at Risk Targeted in Selective Prevention

\begin{tabular}{|c|c|c|c|}
\hline $\begin{array}{l}\text { Tpe of Children } \\
\text { at Risk }\end{array}$ & $\begin{array}{c}k \\
\text { Number of } \\
\text { samples) }\end{array}$ & ES & $-95 \% \mathrm{CI}+95 \%$ \\
\hline Victims of Bullying & 1 & -0.31 & \\
\hline Immigrants NESB & 3 & $0.82 *$ & $(0.30,1.34)$ \\
\hline Sub-threshold depression & 6 & $0.61 *$ & $(0.10,1.12)$ \\
\hline $\begin{array}{l}\text { Difficulties with peer } \\
\text { relationships }\end{array}$ & 3 & 0.17 & $(-0.24,0.57)$ \\
\hline
\end{tabular}

Note: The value in $k$ is the number of samples in outcome measures; $(*)=p<.05$. 
deviant conduct, substance abuse, and depression (Burke, Burke, \& Rae, 1994; World Health Organization, 2001). The aim of this meta-analysis was to determine the effectiveness of psychosocial interventions in preventing anxiety disorders among school-aged children. Nineteen peer-reviewed studies were included all of which provided sufficient data to calculate effect sizes. The analysis of the effect sizes indicates evidence for the effectiveness of CBT interventions to prevent anxiety disorders. Specially, CBT interventions are long-term effective at a selective level, for those children at risk for developing an anxiety disorder.

Even though universal and indicated programs reported positive gains at posttest, at follow-up gains were not maintained and some of the intervention groups got worse. It could be that for universal intervention, a smaller facilitator: student ratio is needed for program implementation along with more booster sessions and family involvement. At the indicated prevention level, children who are already showing anxiety features might need more interventions later in time or multi-component interventions to strengthen the skills learnt. It could be that so far the indicated interventions have addressed the "developmental appropriateness" for the individual's age and maturity, but not for their stage of anxiety (Bond \& Hauf, 2004), therefore not providing the required dosage and specific content to produce visible changes in children who already show features or the actual disorder. Further thought should be given to the idea that it might be better to start early on either very intensive intervention in smaller groups or to provide these children with oneto-one counseling in school with these children. For universal and indicated prevention, further research should explore the differential efficacy of CBT with different dosages, group formats and follow-ups.

The underlying reason for implementing a prevention program lies in the idea that prevention programs not only help to reduce the occurrence of future problems but promotes protective factors or competencies that will help any individual regardless of their risk status (Sandler, 2001). Results from this study showed larger effect sizes for positive future outlook, followed by self-esteem, and self-concept. These are promising news as it is known that optimism makes a big difference in the life of a person in the same way as good self-esteem. No significant improvements were found on children's coping skills. It could be that coping styles are more difficult to change because they are learnt behaviors that become automatic with time.

Groups of children at risk such as immigrants from NESB and sub-threshold depression are more likely to benefit from selective interventions than those whose problems are related to social interactions. It could be that children, who already feel intimidated because of the bullies, do not feel comfortable sharing their personal experiences with the group. Also, having a group comprised of only victims of bullying might fail to provide exposure to positive roles models from typically developing peers. If the purpose is to prevent anxiety disorders, the content of the interventions should target directly the risk (e.g. behavioral inhibition) and the protective factors (e.g. positive self-esteem) related to anxiety disorders (Barrett \& Turner, 2004).

\section{Limitations}

The main limitation of this meta-analysis is the number of studies analyzed. The number of studies was a problem not only because the area of prevention of anxiety disorders in childhood is relatively new, but also because a considerable amount of studies that exist were unusable. A primary problem was the lack of information to complete effect sizes: means and standard deviations, or test statistic values for intervention and control groups, and the unavailability of disaggregated data for samples that were comprised by primary and high school students (Barrett, Sonderegger, \& Sonderegger, 2001; Roome \& Romney, 1985). And, even when studies were analyzed, some studies did not disaggregate data for children at risk and diagnosis-free children. For these studies only a single effect size could be calculated. In order to thoroughly understand how prevention programs work, the availability of disaggregated data is crucial.

Also, because most of the study samples just included children from $4^{\text {th }}$ grade and above, the results of this meta-analysis should be interpreted with caution as they do not represent the primary school level as a whole. There were only three studies including $1^{\text {st }}$ and $2^{\text {nd }}$ grade students. In the same way, caution should be made as the efficacy of these interventions was mostly based on children's self-report subjective interpretation of anxiety. Only one study (i.e., Lowry-Wesbter, Barrett \& Lock, 2003) included a clinician's measure.

\section{Further Research}

Despite the prevalence and significant impairment associated with anxiety disorders, prevention research continues to lag far behind from that on childhood aggression, substance abuse, and academic failure. Fortunately, this trend appears to be changing as the number of studies noticeably increased since 2003. It is possible that anxious children may be more difficult to identify than children with aggressive patterns and drug dependency, or than struggling readers (Compton, Burns, Egger, \& Roberston, 2002).

Results suggest several opportunities for further research. More CBT long term studies are needed before strong conclusions are made. In order to understand how prevention works, anxiety should be assessed through a multi-method and multi-informant 
approach (Bernstein, Borchardt, \& Perwien, 1996; Fonseca \& Perrin, 2001). Further studies should try to include clinicians', teachers' and parents' measures and include more protective factors measures that go beyond the assessment of anxiety symptoms such as problem-solving skills and perceived social support. Including a larger sample size is important, especially because attempts to contact study participants again for follow-up are likely to be difficult. Further research should secure permission from participants for followup and use random assignment and uninformed interviewers to increase the quality of the studies.

In the same way, future studies should include explicit information of the active ingredients that make the intervention successful (Bond \& Hauf, 2004; Compton, Burns, Egger, \& Roberston, 2002). Further studies should specify how their intervention works and how does it fit into the theoretical model underlying anxiety disorders. Detailed information about the implementation and evaluation of the program is also needed to decrease the risk of bias and assess the feasibility of transporting universal interventions to other contexts or perhaps to remote areas where psychological services are likely to be absent or sparse (Bond \& Hauf, 2004; Lowry-Webster, Barrett, \& Dadds, 2001). Likewise, as culture has shown to shape the ways in which anxiety is manifest, further studies should reported data on the ethnicity and race of participants. Only three studies in this synthesis provided this type of information.

At a selective level of prevention, it is important to explore how other groups that might be at risk for anxiety could benefit from CBT interventions. For example, children with obesity and children with learning disabilities (LD), an increasingly prevalent group that has shown to be at risk due to their social and emotional difficulties, and low self-concept (Gallegos, Langley \& Villegas, in press; Margalit \& Zak, 1984; Sharma, 2004; Svetaz, Ireland, \& Blum, 2000). Likewise, as CBT has found to be a successful intervention for immigrants, it will be interesting to explore its effectiveness with Mexican and Mexican-American children in the United States. A common problem of Mexican immigrants in the U.S. is that their language problems and sense of loosing their cultural identity produces significant distress and high levels of anxiety (Valenzuela, 1998). It will also be interesting to explore children's optimal age for receiving a prevention program and the predictors of treatment outcome (e.g. treatment fidelity and gender).

\section{Implications for Practice}

Even with the limitations described above, several implications can be drawn.

Anxiety disorders, the most prevalent lifetime disorders, create enormous short-term and long-term costs for education systems, with negative impacts manifested throughout society. As a core potential benefit of preventing and reducing the incidence of anxiety disorders within a community is decreasing the risk of a myriad of societal problems such as substance abuse and depression, which is expected to become the second-ranked caused of disease burden in 2020 (World Health Organization, 2004).

Substance and drug abuse have been a massive and pervasive problem in schools. For example, statistics from the U.S. showed that by the time students complete high school, $70 \%$ have smoked cigarettes, $81 \%$ have drank alcohol, $47 \%$ have used marijuana, and $24 \%$ have used some other illicit drug (The National Center on Addiction and Substance Abuse at Columbia University, 2001). Delaying prevention of these problems will burden schools and societies to absorb the costs and destructive implications: class disruption and violence, increase in special education and counseling programs, teacher turnover, truancy, children left behind, property damage and injury among others. Therefore, prevention of the substance abuse than can begin with childhood psychopathology is certainly important to address.

As late childhood is a critical time for the development of an anxiety disorder (Kessler et al., 2005), providing prevention programs during school time will help by (1) increasing the attrition rate of students benefiting from a psychotherapy (Lowry-Webster, Barrett, \& Dadds, 2001), (2) avoiding stereotype due to labeling, particularly when provided to the whole classroom (Smart, 2001), (3) increasing the awareness of psychopathology among teachers, thus providing early screening and referral to students that need further help (Dadds, Spence, Holland, Barrett, \& Laurens, 1997; Dozois \& Dobson, 2004), (4) promoting students competence through positive coping skills and prevent unhealthy behaviors is their formative years of personality development, and (5) providing positive role models from peers and teachers (Lowry-Webster, Barrett, \& Lock, 2003). Likewise, effective prevention programs could lead to indirect outcomes such as helping students reduce their negative self-perception (Bryan, Burstein, \& Ergul, 2004), enhancing their coping skills, and establishing strong relationships within the community (Lowry-Webster, Barrett, \& Lock, 2003).

Because anxiety disorders have been associated with conditions highly prevalent in schools such as learning disabilities, and externalizing disorders such as: ADHD, oppositional defiant disorder, and conduct disorders, schools can explore the benefit from prevention programs to reduce the severity of a student experiencing these type of problems (Noel, Hoy, King, Moreland, \& Jagota, 1992; Ollendick, Shortt, \& Sander, 2005). When selecting a prevention program, schools should pay careful attention to the particular characteristics of the group at risk and evaluate how 
the intervention does addresses the risk and protective factors for anxiety disorders.

Particularly for children with LD, providing a psychosocial intervention to prevent anxiety disorders could aid in their academic improvement, as research has shown a strong connection between these two (Martinez \& Semrud-Clikerman, 2004). It is evident that children with LD need to improve their self-concept and learn coping strategies to manage their anxiety and helpfulness (Margalit \& Raviv, 1984), and CBT interventions appear to be a potential option for the delivery of these skills. Although CBT has not been implemented for anxiety prevention in children with LD, it has shown its effectiveness by reducing test anxiety and increasing the academic self-esteem of high school and college students with LD (Walchelka \& Katz, 1999).

Besides implementing a psychosocial intervention to prevent anxiety disorders in children, there are other things that schools could do to reduce the risk of developing an anxiety disorder. First, educating the community (i.e. parents and teachers) about risk and protective factors for anxiety and its course of development. Research has shown for students with LD, parents and school connectedness are the major protective factors for the development of a psychological problem (Svetaz, Ireland, \& Blum, 2000). For example, educating parents about the importance of establishing secure parent-child attachment and positive relationships in the first two years of life could reduce the child's risk for developing an anxiety disorder (Al-Yagon \& Mikulincer, 2004; Weiner, 2004). Also, educating parents about child-management and coping skills has shown to be fundamental (Barrett, Dadds, \& Rapee, 1996). Including some of the work form Mental Health for teacher training is crucial.

The findings of this meta-analysis point to the potential of CBT anxiety prevention programs when provided during primary school years, especially for those children at risk. This is not to suggest that children receiving these programs would not experience anxiety symptoms during stressful times, or that further intervention will not be needed. Prevention programs work by enhancing the children's emotional resilience, and as a consequence, children could cope better with stressful situations and learn to manage their anxiety. At all levels of prevention, programs should adopt a "ecological systems perspective" by seeking to combine efforts through multiple systems (e.g. family networks, community organizations, diverse personnel from school, etc.) within the community (Bond \& Hauf, 2004).

\section{References}

Al-Yagon, M. \& Mikulincer, M. (2004). Patterns of close relationships and socioemotional and academic adjust- ment among school-aged children with learning disabilities. Learning Disabilities Research and Practice, 19, 1219.

Barrett, P., Dadds, M. W., \& Rapee, R. M. (1996). Family treatment of childhood anxiety: A controlled trial. Journal of Consulting \& Clinical Psychology, 64, 333-342.

Barrett, P., Sonderegger, R., \& Sonderegger, N. L. (2001). Evaluation of an anxiety-prevention and positive-coping program (FRIENDS) for children and adolescents of nonEnglish-speaking background. Behaviour Change, 18, 78-91.

Barrett, P. \& Turner, C. (2001). Prevention of anxiety symptoms in primary school children: Preliminary results from a universal school-based trial. The British Journal of Clinical Psychology, 40, 399-410.

Barrett, P. \& Turner, C. (2004). Prevention of childhood anxiety and depression. In P. Barrett \& T. H. Ollendick (Eds.), Handbook of interventions that work with children and adolescents: Prevention and treatment (pp. 429-474). England: John Wiley \& Sons Inc.

Barrett, P. \& Farrell, L. (2007). Behavioural intervention for childhood anxiety. In J. M. Bries-meister \& C. E. Schaefer (Eds.), Handbook of parent training: Helping parents prevent and solve problem behaviours (pp. 133163). New Jersey: Wiley

Bernstein, G. A., Borchardt, M. D., \& Perwien, B. A. (1996). Anxiety disorders in children and adolescents: A review of the past 10 years. Journal of American Academic Child and Adolescent Psychiatry, 35, 1110-1119.

Bernstein, G. A., Layne, A. E., Egan, E. A., \& Tennison, D. M. (2005). School-based intervention for anxious children. Journal of American Academic Child and Adolescent Psychiatry, 44, 1118-1127.

Bond, L. A. \& Hauf, A. M. C. (2004). Taking stock and putting stock in primary prevention: Characteristics of effective programs. The Journal of Primary Prevention, 24, 199-221.

Bryan, T., Burstein, K., \& Ergul, C. (2004). The socio-emotional side of learning disabilities: A science-based presentation of the state of art. Learning Disability Quarterly, 27, 21-30.

Burke, J. D., Burke, K. C., \& Rae, D. S. (1994). Increased rates of drug abuse and dependence after onset of mood and anxiety disorders in adolescence. Hospital and Community Psychiatry, 45, 451-455.

Caraveo-Anduaga, J. J. \& Comenares-Bermúdez, E. (2002). Los trastornos psiquiátricos y el abuso de substancias en México: Panorama epidemio-lógico. Salud Mental, 25(2), 9-15.

Chemtob, C.M., Nakashima, J., \& Carlson, J.G. (2002). Brief treatment for elementary school children with disaster-related posttraumatic stress disorder: A field study. Journal of Clinical Psychology, 58, 99-112.

Chemtob, C.M., Nakashima, J., \& Hamada, R.S. (2002). Psychosocial intervention for postdisaster trauma symptoms in elementary school children: A controlled community field study. Archives of Pediatric Adolescent Medicine, 56, 211-216. 
Cohen, J. (1988). Statistical power analysis for the behavioral sciences (2nd ed.). Hillsdale, NJ.: Lawrence Erlbaum.

Cohen, J. (1992). A power primer. Psychological Bulletin, $112,155-159$.

Compton, S. N., Burns, B. J., Egger, H. L., \& Roberston, E. (2002). Review of the evidence base for treatment of childhood psychopatology: Internalizing disorders. Journal of Consulting \& Clinical Psychology, 70, 12401266.

Craske, M. G. (1999). Anxiety disorders: Psychological approaches to theory and treatment. Boulder, Colorado: Westview Press.

Curtis, L. J., Dooley, M. D., Lipman, E. L., \& Feeny, D. H. (2001). The role of permanent income and family structure in the determination of child health in Canada. Health Economics, 10, 287-302.

Dadds, M. R., Holland, D. E., Laurens, K. R., Mullins, M., Barrett, P., \& Spence, S. H. (1999). Early intervention and prevention of anxiety disorders in children: Results at 2year follow up. Journal of Consulting \& Clinical Psychology, 67, 145-150.

Dadds, M. R., Spence, S. H., Holland, D. E., Barrett, P., \& Laurens, K. R. (1997). Prevention and early intervention for anxiety disorders: A controlled trial. Journal of Consulting \& Clinical Psychology, 65, 627-635.

Davis, M. K. \& Gidycz, C. A. (2000). Child sexual abuse prevention programs: A meta-analysis. Journal of Clinical Child Psychology, 29, 257-265.

De Cuyper, S., Timbremont, B., Braet, C., De Backer, V., \& Wullaert, T. (2004). Treating depressive symptoms in schoolchildren: A pilot study. European Child \& Adolescent Psychiatry., 13, 105-114.

DeRosier, M. E. (2004). Building relationships and combating bullying: Effectiveness of a school-based social skills group intervention. Journal of clinical child and adolescent psychology : the official journal for the Society of Clinical Child and Adolescent Psychology, American Psychological Association, Division 53., 33, 196-201.

DeRosier, M. E. \& Marcus, S. R. (2005). Building friendships and combating bullying: Effective-ness of S.S.GRIN at one-year follow-up. Journal of clinical child and adolescent psychology : the official journal for the Society of Clinical Child and Adolescent Psychology, American Psychological Association, Division 53, 34, 140-150.

DerSimonian, R. \& Laird, N. (1986).Meta-analysis in clinical trials. Control Clinical Trials, 7, 177-188.

Donovan, C. L. \& Spence, S. H. (2000). Prevention of childhood anxiety disorders. Clinical Psychology Review, 20, 509-531.

Dozois, D. J. A. \& Dobson, K. S. (2004). The prevention of anxiety and depression: Theory, research, and practice (1st ed.). Washington, DC: American Psychological Association.

Dozois, D. J. A. \& Westra, H. A. (2004). The nature of anxiety and depression: Implications for prevention. In D. J. A. Dozois \& K. S. Dobson (Eds.), The prevention of anxiety and depression: Theory, research and practice. (pp.
9-41). Washington, D.C.: American Psychological Association.

Essau, C. A., Conradt, J., \& Petermann, F. (2000). Frequency, comorbidity, and psychological impairment of anxiety disorders in German adolescents. Journal of Anxiety Disorders, 14, 263-279.

Essau, C. A. \& Peterman, F. (Eds.). (2001). Anxiety disorders in children and adolescents: epidemiology, risk factors and treatment. East Sussex: Brunner-Routledge.

Feldner, M. T., Zvolensky, M. J., \& Schmidt, N. B. (2004). Prevention of anxiety psychopatology: A critical review of the empirical literature. Clinical Psychology: Science and Practice, 11, 405-424.

Fox, C. L. \& Boulton, M. J. (2003). Evaluating the effectiveness of a social skills training (SST) programme for victims of bullying. Educational Research, 45, 231-247.

Fonseca, A. C. \& Perrin, S. (2001). Clinical phenomenology, classification and assessment of anxiety disorders in children and adolescents. In W. K. Silverman \& P. A. Treffers (Eds.), Anxiety disorders in children and adolescents: Research, assessment, and intervention (pp. 126-158). Cambridge, UK: Cambridge University Press.

Garland, A. F., Hough, R. L., McCabe, K. M., Yeh, M., Wood, P. A., \& Aarons, G. A. (2001). Prevalence of psychiatric disorders of youth across five sectors of care Journal of the American Academy of Child \& Adolescent Psychiatry, 40, 409-418.

Ghaderi, A., Martensson, M., \& Schwan, H. (2005). "Everybody's Different": A primary prevention program among fifth grade school children. Eating Disorders: The Journal of Treatment \& Prevention, 13, 245-259.

Gordon, R. (1987). An operational classification of disease prevention. In J. Steinberg \& M. Silverman (Eds.), Preventing mental disorders in school-age children: A review of the effectiveness of prevention programs. (pp. 20-26). Washington, D.C.: Department of Health and Human Services: National Institute of Mental Health.

Hirshfeld-Becker, D. R. \& Biederman, J. (2002). Rationale and principle for early intervention with young children at risk for anxiety disorders. Clinical Child and Family Psychology Review, 5(3), 161-172.

Higgins J. \& Altman D. Chapter 8: Assessing risk of bias in included studies. In: Higgins JPT, Green S, eds. Cochrane Handbook for Systematic Reviews of Interventions, Version 5.0.1 (updated September 2008). The Cochrane Collaboration. 2008 Available from http://www.cochranehandbook.org.

Kashani, J. H. \& Orvaschel, H. (1990). A community study of anxiety in children and adolescents. American Journal of Psychiatry, 147, 313-318.

Kendall, P. C. (2006). Guiding theory. In P. C. Kendall (Ed.), Child and adolescent therapy (pp. 3-32). New York, NY: The Guildford Press.

Kendall, P. C. \& Suveg, C. (2006). Treating anxiety disorders in youth. In P. C. Kendall (Ed.), Child and adolescent therapy (pp. 243-296). New York, NY: The Guildford Press.

Kessler, R. C. (1982). A disaggregation of the relationship 
between socioeconomic status and psychological distress. American Sociological Review, 47, 752-764.

Kessler, R. C., Berglund, P., Bemler, O., Jin, R., Merikangas, K. R., \& Walters, E. E. (2005). Lifetime prevalence and age-of-onset distributions of DSM-IV disorders in the national comorbidity survey replication. Archives of General Psychiatry, 62, 593-768.

Lipsey, M. W. \& Wilson, D. B. (2000). Practical metaanalysis (Vol. 49). Thousand Oaks, California: SAGE Publications.

Lock, S. \& Barrett, P. (2003). A longitudinal study of developmental differences in universal preventive intervention for child anxiety. Behaviour Change, 20(4), 183-199.

Lowry-Webster, H. M., Barrett, P., \& Dadds, M. R. (2001). A universal prevention trial of anxiety and depressive symptomatology in childhood: Preliminary data from an Australian study. Behaviour Change, 18, 36-50.

Lowry-Webster, H. M., Barrett, P., \& Lock, S. (2003). A universal prevention trial of anxiety symptomology during childhood: Results at 1-year follow-up. Behaviour Change, 20, 25-43.

Margalit, M. \& Zak, I. (1984). Anxiety and self-concept of learning-disabled children. Journal of Learning Disabilities, 17, 537-539.

Martinez, R. S. \& Semrud-Clikerman, M. (2004). Emotional adjustment and school functioning of young adolescents with multiple versus single learning disabilities. Journal of Learning Disabilities, 37, 411-420.

Masten, A. S. (2001). Ordinary magic: Resilience processes in development. American Psychologist, 56, 227-238

Misfud, C. \& Rapee, R. M. (2005). Early intervention for childhood anxiety in a school setting: Outcomes for an economically disadvantaged population. Journal of American Academic Child and Adolescent Psychiatry, 44, 996-1004.

National Institute of Mental Health. (1999). Fact sheet: Anxiety disorders research. Retrieved November10, 2004, from http:www.nimh.nih. gov/healthinformation/ anxietymenu.cfm

Neil, A. L. \& Christensen, H. (2009). Efficacy and effectiveness of school-based prevention and early intervention programs for anxiety. Clinical Psychology Review, 29, 208-215

Noel, G., Hoy, C., King, M., Moreland, C., \& Jagota, M. (1992). The MMPI-2 profile of adults with learning disabilities in university and rehabilitation settings. Journal of Learning Disabilities, 25, 386-395.

Ollendick, T. H., Shortt, A. L., \& Sander, J. B. (2005). Internalizing disorders in childhood and adolescence. In J. E. Maddux \& B. A. Winstead (Eds.), Psychopatology: Foundations for a contemporary understanding. (pp. 353376.). Man-wah, New Jersey: Erlbaum Associates, Inc.
Ragan, L. \& Hiebert, B. (1987). Kiddie QR (Quieting Reflex): Field testing a relaxation program for young children. The School Counselor, 34(4), 273-281.

Roome, J. R. \& Romney, D. M. (1985). Reducing anxiety in gifted children by inducing relaxation. Rooper Review, 7(3), 177-179.

Sandler, I. (2001). Quality and ecology of adversity as common mechanisms of risk and resilience. American Journal of Community Psychology, 29, 19-55.

Sharma, G. (2004). A comparative study of personality characteristics of primary-school students with learning disabilities and their non-learning disabled peers. Learning Disability Quarterly, 27, 127-140.

Shapiro, F. (1995). Eye movement desensitization and reprocessing. New York: Guilford Press.

Smart, J. (2001). Disability, society and the individual. Austin: Pro-Ed.

Stein, B. D., Jaycox, L. H., Kataoka, S. H., Wong, M., Tu, W., Elliott, M. N., et al. (2005). A mental health intervention for schoolchildren exposed to violence: A randomized controlled trial. The Journal of the American Medical Association, 290, 603-611.

Svetaz, M. V., Ireland, M., \& Blum, R. (2000). Adolescents with learning disabilities: Risk and protective factors associated with emotional well-being. Findings from the national longitudinal study of adolescent health. Journal of Adolescent Health 27, 340-348.

Tomb, M. \& Hunter, L. (2004). Prevention of anxiety in children and adolescents in a school setting: The role of the school-based practitioners. Children \& Schools, 26(2), 87-101.

The National Center on Addiction and Substance Abuse at Columbia University. (2001). Malignant neglect: Substance abuse in America's schools. New York, NY.: The National Center on Addiction and Substance Abuse at Columbia University.

Valenzuela, J. M. (1998). El color de las sombras: Chicanos, identidad y racismo. Universidad Iberoamericana, México, D.F.

Walchelka, D. \& Katz, R. C. (1999). Reducing test anxiety and improving academic self-esteem in high school and college students with learning disabilities. Journal of Behavior Therapy, 30, 191-198.

Weiner, J. (2004). Do peer relationships foster behavioral adjustment in children with learning disabilities? Learning Disability Quarterly, 27, 21-30.

World Health Organization. (2004). Prevention of mental disorders: Effective interventions and policy options: Summary report: World Health Organization, Dept. of Mental Health and Substance Abuse, in collaboration with the Prevention Research Centre of the Universities of Nijmegen and Maastricht.

Manuscrito recibido: 29/04/2011

Revisión recibida: 14/05/2011

Manuscrito recibido: 18/05/2011 